\title{
P. F Correction Control of 3- $\Phi$ Induction Motor Drive through PWM Current Controlled Technique
}

\author{
G. Venkataratnam, K. Ramakrishnaprasad, and N. Yadaiah
}

\begin{abstract}
This Paper presents power factor (P.F) correction control of three phase Induction motor drive using Pulse Width Modulation (PWM) current control technique. Single-phase boost rectifier is used to obtain near unity power factor and to reduce harmonic distortion in the main supply. This is illustrated in MATLAB/SIMULINK environment.
\end{abstract}

Index Terms-Power factor correction boost-converter, PWM inverter, three phase Induction motor drive.

\section{INTRODUCTION}

Variable Voltage Variable Frequency (VVVF) drive of an induction motor is widely used both in industrial and domestic applications. Especially in domestic applications a single-phase input and three-phase output inverters for motor drive have become popular. In AC systems, poor power factor causes to increases the current loading on all wiring and components, thus leading to higher capital and operating costs, shortened equipment lifetime and higher utility bills. Power factor correction (PFC) converters holding an important area of study and research in power electronics [1].

The AC-DC converters provide stable DC voltage at the output with high input power factor [2]. PWM converter is one of the solutions for the problems of the converter circuit.[3] the control scheme of the converter circuit of the converter-inverter system.[4] the design method of the converter inverter system based on the loss of controllability and the output harmonic distortion. However, in designing high efficiency VVVF drive system for practical applications, it is the motor efficiency that should be taken into consideration [5].

The output of an uncontrolled converter can be controlled by controlling the performance of rectifiers[6]boost converters provide regulated dc output voltage at unity power factor and reduced Total harmonic distortion of input ac current ,These converters have found widespread use in various applications due to the advantages of high efficiency, high power density and inherent power quality improvement at ac input and dc output[7] The magnetic flux control PWM method is used as the PWM strategy of the inverter. The modulation factor of the inverter which uses controllable dc

Manuscript received February 15, 2012; revised March 16, 2012.

G. Venkataratnam is with the Department of Electrical Engineering Osmania University Hyderabad (e-mail:venkataratnam.gera@gmail.com).

K. Ramakrishnaprasad is with Department of Electrical and Electronics Engineering, SaiSpurthi Instate of Technology Sathupally, Khammam.

N. Yadaiah is with the Electrical and Electronics Engineering Department, Jawaharalal Nehru Technological University, Hyderabad, Kukatapally, Hyderabad-500085 (e-mail:svpnarri@yahoo.com). voltage is studied in order to make motor efficiency high. The remainder of the paper is organized as follows Section (II) focuses on the system configuration. Section (III) describes the PWM control technique Section (IV) Modeling of boost PFCconverters Section (V) Implementation of proposed technique Section (VI) Results and discussion.

\section{SySTEM CONFIGURATION}

A Boost converter (DC-DC converter) in continuous conduction mode is an excellent choice for the power stage of an active power factor corrector because the input current is continuous and this produces the lowest level of conducted noise and the best input current waveform. The boost regulator input current must be forced or programmed to be proportional to the input voltage waveform for power factor correction. Feedback is necessary to control the input current and either peak current mode control or average current mode control may be used as discussed before. The converter consisting boost converter is shown in Fig. 1 along with Power Factor Correction circuit.

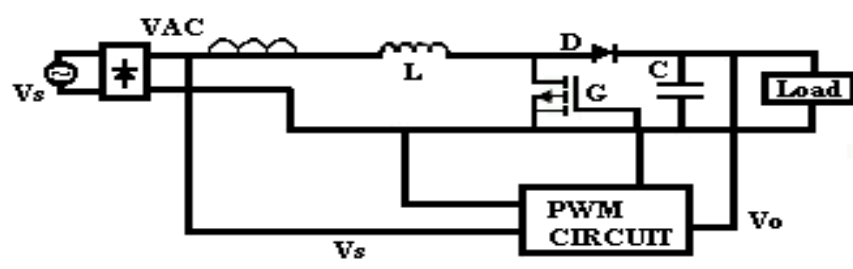

Fig. 1. Principle scheme of Boost Converter employing average current control.

In the Peak current mode control approach, the peak current of the inductor is used to force the input current to follow the reference. This approach has a low gain, wide bandwidth current loop which generally makes it unsuitable for a high performance power factor corrector since there is a significant error between the programming signal and the current. This will produce distortion and a poor power factor.

For Average current mode control An amplifier is used in the feedback loop around the boost power stage so that the input current tracks the programming signal with tiny error. This is the advantage of average current mode control and it is makes active power factor correction possible.

A diode rectifier effects the AC/DC conversion, while the controller operates the switching device MOSFET in such a way to properly shape the input current $i_{L}$, according to its reference. The output capacitor absorbs the input power pulsation, allowing a small ripple of the output voltage $V_{0}$.

The block diagram of the drive employing Power Factor Correction (PFC) is shown in Fig. 2 and the circuit 
configuration is shown in Fig.3.

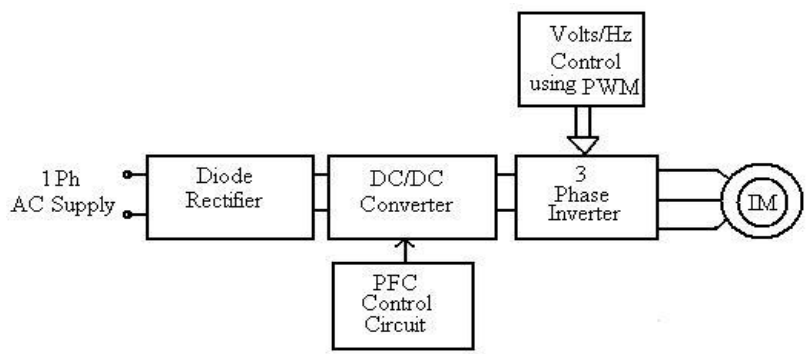

Fig. 2. Block Diagram of Drive with PFC

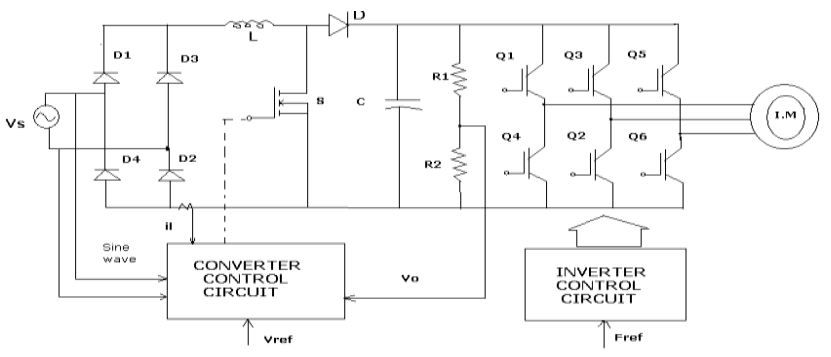

Fig. 3. Circuit Configuration

PFC Converter topologies considered in this above Single phase AC supply is given to the diode rectifier And then it will gives pulsated dc connected to the boost converter it will boost up the voltage and potential divider will check the input and output voltage levels and given to the input of inverter and it will gives ac output and connected to load

\section{PWM CONTROL TECHNIQUE}

In PWM based power factor correction approach, the power-switching device switching according to pulse pattern of pulse-width-modulation mode of operation. Harmonics exists on source line and load, somewhat Harmonic problems can be eliminated by introducing filter at the input. The non-ideal character of the input current drawn by these rectifiers creates number of problems like increase in reactive power, high input current duty cycle of the boost switch connected at the output of converter. The switching type of conversion can introduce distortion and generate low input power factor, lower rectifier efficiency Large input voltage distortion etc.

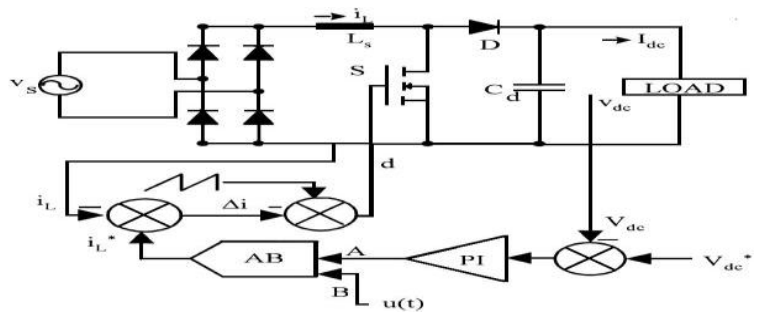

Fig. 4. PFC circuit employing PWM Current Controller

Basically this technique switching frequency of active power switch is constant, but turn-on and turn-off mode is variable. Fig 4. Shows the PFC circuit configuration employing PWM. In this method, the reference current and actual current are compared in the comparator. This error signal is amplified and compared to a fixed frequency carrier wave to generate the pulses to the MOSFET. The carrier wave is generally a saw-tooth wave whose frequency is equal to the frequency at which the boost converter is designed. This method has advantages like simple configuration, ease of analysis and control, lowest voltage and current stress. Therefore it is extensively used in PFC circuits. For the minimization of converter size PWM technique and generation of significant switching loss.

\section{Modeling OF Boost PFC CONVERTER}

The modeling a PFC converter has first-order differential equations, for describing the state of current through inductor (s) and voltage across capacitor (s). The discrete switching function obtained from the controller is also incorporated into the modeling equations to obtain details of switching ripple. Additionally, other components of the PFC converter system, such as the single-phase ac supply, feedback controller and load, are also modeled and solved concurrently to simulate the entire system. All the different components of the PFC converter are modeled separately and then integrated to form a comprehensive model of the system.

Simulation parameters of the converter is carried out under similar conditions with a sinusoidal ac source, $230 \mathrm{~V} \mathrm{ac}, 50 \mathrm{~Hz}$ input, $500 \mathrm{~W}$ converter with a switching frequency of $50 \mathrm{KHz}$. The output voltage is $400 \mathrm{~V}$ dc

\section{A. Supply System}

Under normal operating conditions the supply system can be modeled as a sinusoidal voltage source of amplitude $V_{m}$ and frequency fs. The instantaneous voltage is,

$$
\mathrm{V}_{\mathrm{s}}(\mathrm{t})=\mathrm{V}_{\mathrm{m}} \sin \omega \mathrm{t}
$$

where $\omega=2 \pi \mathrm{fs}$ electrical radians/second and $\mathrm{t}$ is instantaneous time.

In the input is rectified line voltage $\mathrm{V}_{\mathrm{d}}(\mathrm{t})$ which can be given as,

$$
\mathrm{V}_{\mathrm{d}}(\mathrm{t})=\mathrm{V}_{\mathrm{s}}(\mathrm{t})=\mathrm{V}_{\mathrm{m}} \sin \omega \mathrm{t}
$$

From the sensed supply voltage, an input-voltage template $\mathrm{u}(\mathrm{t})$ is estimated for converter topologies with ac side inductor as,

$$
\mathrm{u}(\mathrm{t})=\mathrm{V}_{\mathrm{s}}(\mathrm{t}) / \mathrm{V}_{\mathrm{m}}
$$

The input-voltage template for converter topologies with a dc side inductor is obtained from,

$$
\mathrm{u}(\mathrm{t})=\mathrm{V}_{\mathrm{s}}(\mathrm{t}) / \mathrm{V}_{\mathrm{m}}
$$

\section{B. Feedback Control :( Current Mode Control)}

PFC converters function with feedback control. Figure 3 shows a typical control scheme for PFC converters-the current mode control. This control scheme ensures regulated dc output voltage at high input power factor. Here the control philosophy is fairly intuitive. The output dc voltage regulator generates a current command, which is the amount of current required to regulate the output voltage to its reference value. The output of the dc regulator is then multiplied with a template of input voltage to generate an input current 
reference. This current reference has the magnitude required to maintain the output dc voltage close to its reference value and has the shape and phase of the input voltage-an essential condition for high input power factor operation.

\section{DC voltage Controller}

A proportional integral (PI) voltage controller is selected for zero steady-state error in dc voltage regulation. The dc voltage $\mathrm{Vdc}$ is sensed and compared with the set reference voltage $\mathrm{V}_{\mathrm{dc}} *$. The resulting voltage error $\mathrm{V}_{\mathrm{e}}(\mathrm{n})$ at the $\mathrm{nth}$ sampling instant is,

$$
V_{e}(n)=V_{d c} *_{-} V_{d c}(n)
$$

The output of the PI voltage regulator $\mathrm{V}_{\mathrm{o}}(\mathrm{n})$ at the nth sampling instant of the PI controller will be,

$$
V_{o}(n)=V_{o}(n-1)+K_{p}\left\{V_{e}(n)-V_{e}(n-1)\right\}+K_{i} V_{e}(n)
$$

Here $K p$ and $K i$ are the proportional and integral gain constants, respectively; $V_{e}(\mathrm{n}-1)$ is the error at the (n-1) the sampling instant. The output of the controller $\mathrm{V}_{\mathrm{o}}(\mathrm{n})$ after limiting to a safe permissible value is taken as the amplitude of the input current reference.

\section{1) Reference supply current generation:}

The input voltage template $u(t)$ obtained from the sensed supply voltage is multiplied by the amplitude of the input current reference A to generate a reference current. The instantaneous value of the reference current is given as,

$$
i_{L} *=A B
$$

where $\mathrm{B}$ is the input voltage template $\mathrm{u}(\mathrm{t})$.

2) Active wave shaping of input current:

The input current error is the difference between the reference current and the actual current $\left(\Delta \mathrm{i}_{\mathrm{L}}{ }^{*}-\mathrm{i}_{\mathrm{L}}\right)$. A number of current control strategies can be employed to contain the current error within the desired range so that the input current tracks its reference with minimal error. The switching logic is dependent on the type of converter topology used. In the present work used the both hysteresis current controller and PWM current controller.

\section{Modeling Devices and Selection of Load}

The various devices and elements in PFC converters can exhibit highly complex dynamics, however, in this work their ideal behavior is modeled for simplicity and appropriateness.

The inductor is modeled as a linear inductance Ls (or L1 and L2 in multiple inductor topologies) with a dc resistor. Similarly, a capacitor is modeled with capacitance $\mathrm{C}_{\mathrm{d}}$ (or $\mathrm{C} 1$ and $\mathrm{C} 2$ in topologies with multiple capacitors). The equivalent series resistance of capacitors is not considered.

The Load of converters is modeled as resistive loads having resistance $\mathrm{R}$.

\section{E. Semiconductor Switches}

Semiconductor switches, MOSFETS and diode D are modeled as for pure ON-OFF switches. No snubbers or non-idealities in the switches are modeled. Power circuit: The power circuit is modeled by first-order differential equations describing the circuit behavior. These modeling equations are obtained to the power circuit in the following section.

\section{F. Single-Phase Boost PFC Converter}

This is by far the most popular topology. It is used extensively for front-end high power factor rectification in offline power supplies and electric drive applications. The boost converter (shown in Figure 6) is modeled using two differential equations for inductor current $\mathrm{i}_{\mathrm{L}}$ and $\mathrm{dc}$ link capacitor voltage $V_{d c} *$.

$$
\begin{aligned}
& p i_{L}=\left(V_{d^{-}} V_{p}\right) / L s-r\left(i_{L} / L_{s}\right) \\
& p V_{d c}=(i p-V d c / R) / C_{d}
\end{aligned}
$$

where $\mathrm{P}$ is the differential operator $(d / d t) . V_{p}$ is the PWM voltage across the switch and is defined as,

$$
V_{p}=v_{d c}(1-d)
$$

$i_{p}$ is the current through the boost diode and is defined as

$$
i_{p}=i_{L}(1-d)
$$

Here $\mathrm{d}$ is the switching signal obtained from the current regulation loop. Its value is $1(\mathrm{ON})$ or $0(\mathrm{OFF})$ depending upon the state of the switch $\mathrm{S}$. As is obvious from the circuit topology and modeling equations, the dc output voltage in this converter has to be kept higher than the peak value of the input voltage to allow current control.

\section{IMPLEMENTATION OF PROPOSED TECHNIQUE}

VVVF output is generated from the inverter by using the principle of PWM, which controls the ON/OFF periods of the inverter devices [6]. The devices used are self-commutation device like GTO's, IGBT etc. as thyristors require forced commutation circuits. Because an inverter contains switching elements, it is possible to control the output voltage frequency as well as optimize the harmonics by performing multiple switching within the inverter.

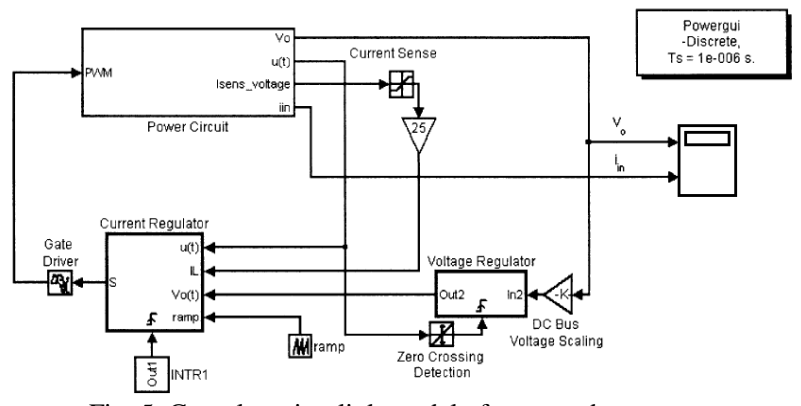

Fig. 5. Complete simulink model of proposed system

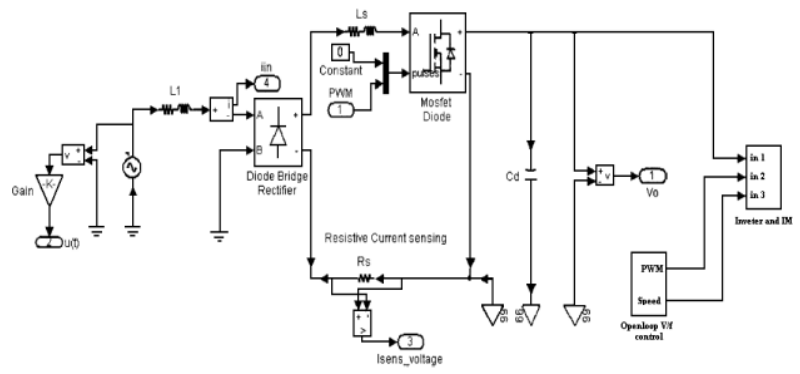

Fig. 6. Boost converter circuit 


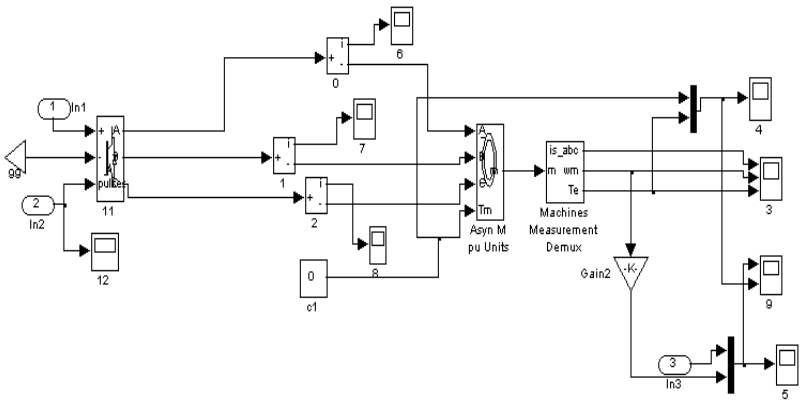

Fig. 7. Inverter induction motor power circuits

\section{RESULTS AND DISCUSSION}

In order to illustrate the proposed method, the following parameters are considered.

$\begin{array}{ll}\text { Input voltage } & =230 \mathrm{~V}_{\text {R.M.S. }} \\ \text { Frequency } & =50 \mathrm{~Hz} \\ \text { Inductance } & =1100 \mu \mathrm{H} \\ \text { Capacitance } & =470 \mu \mathrm{F} \\ \text { Voltage controller } & =\text { Discrete PI } \\ \text { Current controller } & =\text { PWM control }\end{array}$

Switching frequency of boost converter $=50 \mathrm{kHz}$

Converter output voltage $\quad=400 \mathrm{~V}$

Inverter switching frequency $\quad=1.05 \mathrm{kHz}$

Three-phase Induction motor $=0.5 \mathrm{HP}, 400 \mathrm{~V}, 50 \mathrm{~Hz}$, 4-pole.

The proposed system is implemented in the MATLAB Environment as given in the previous section. The results are shown as follows:

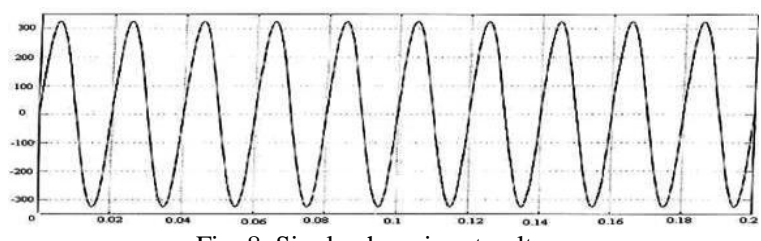

Fig. 8. Single phase input voltage

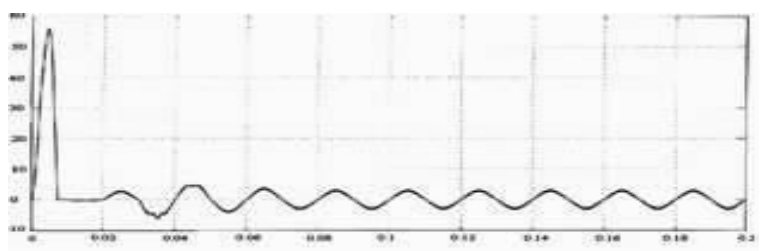

Fig. 9. Single phase input current With PFC

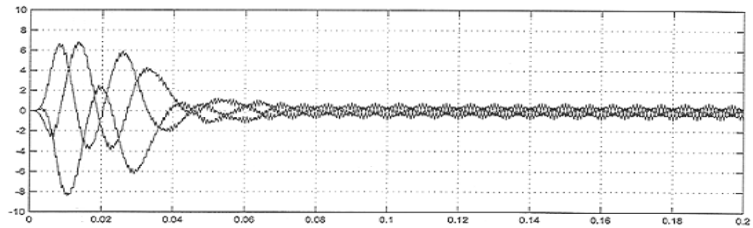

Fig. 10. Three phase rotor currents at With PFC

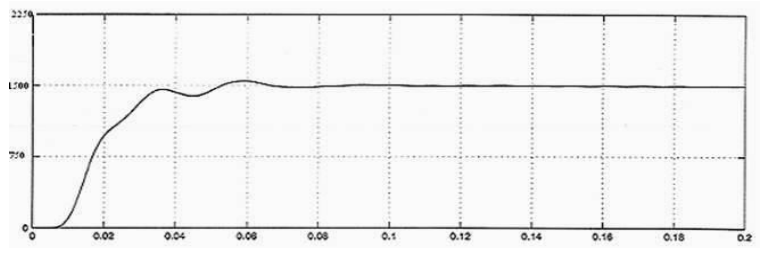

Fig. 11. Motor speed at no load with PFC

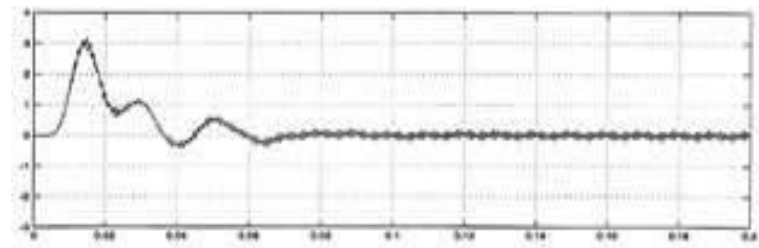

Fig. 12. Motor torque at no load with PFC

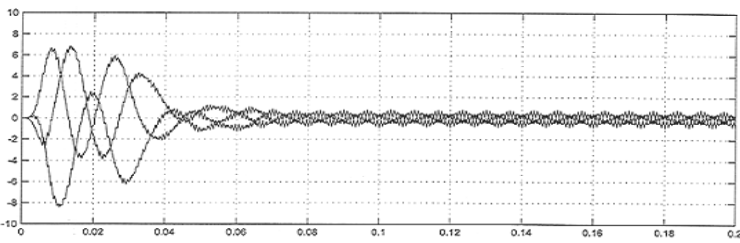

Fig. 13. Three phase rotor currents at without PFC

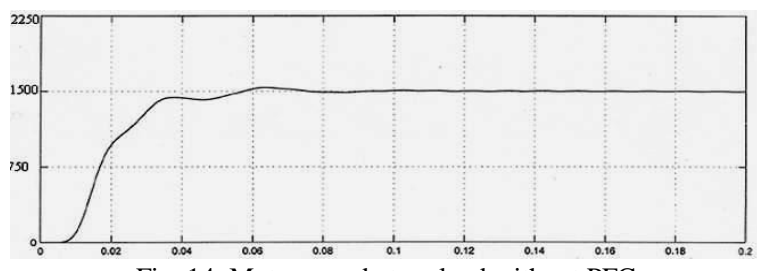

Fig. 14. Motor speed at no load without PFC

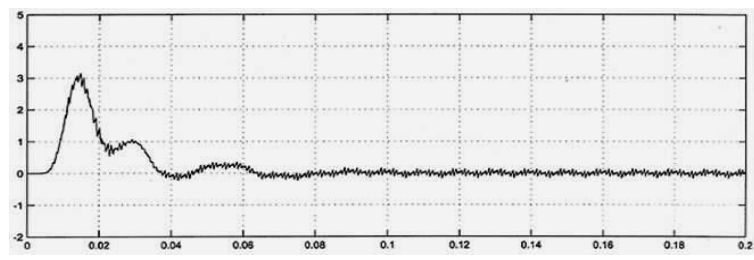

Fig. 15. Motor torque at no load without PFC

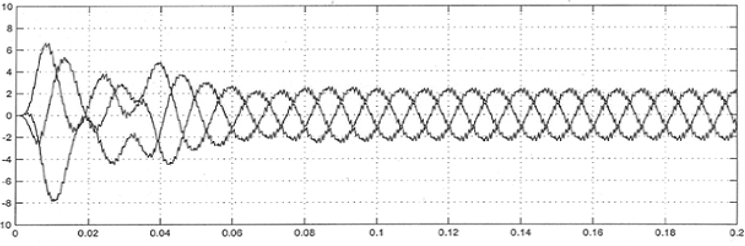

Fig. 16. Three phase rotor currents at half load with PFC

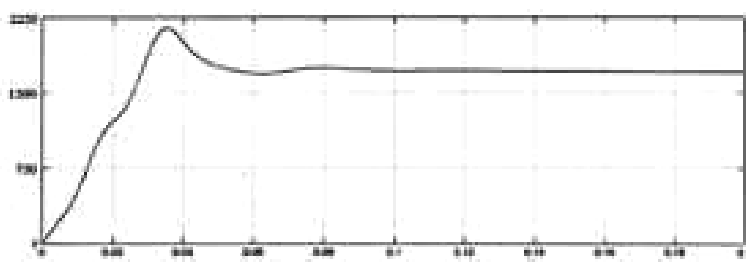

Fig. 17. Motor speed at half load with PFC

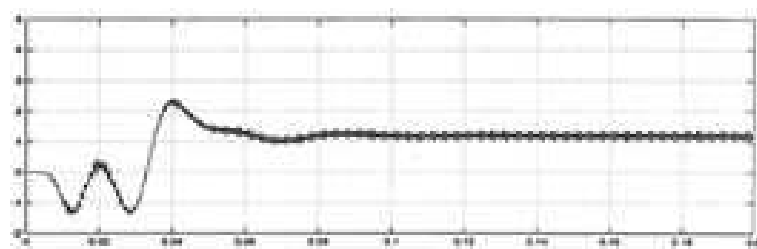

Fig. 18. Motor torque at half load with PFC

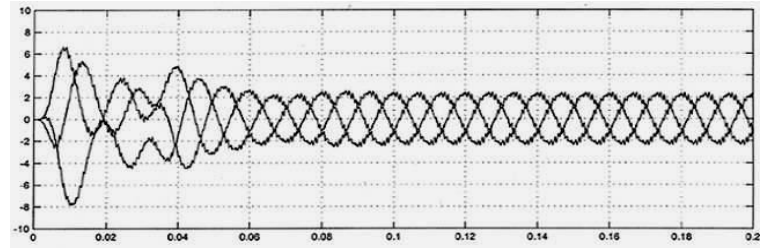

Fig. 19. Three phase rotor currents at half load without PFC 


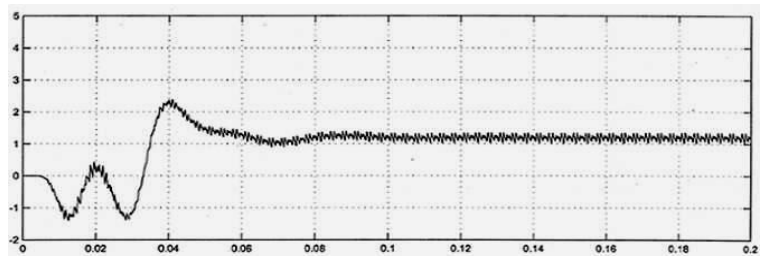

Fig. 20. Motor torque at half load without PFC

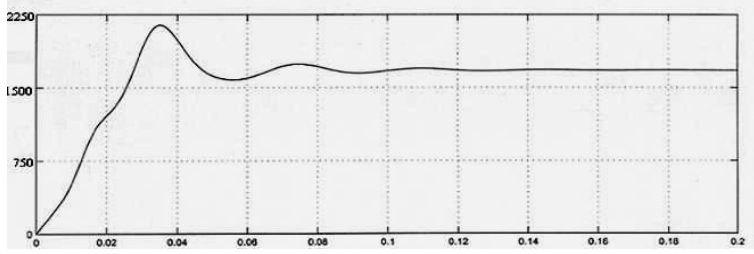

Fig. 21. Motor speed at half load without PFC

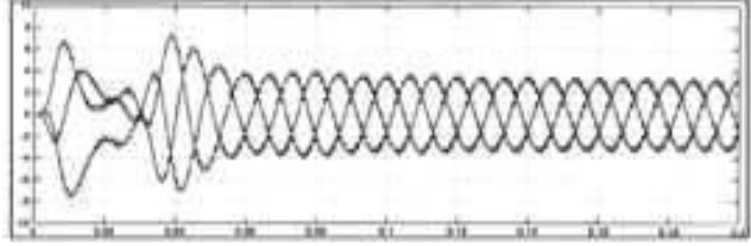

Fig. 22. Three phase rotor currents at full load with PFC

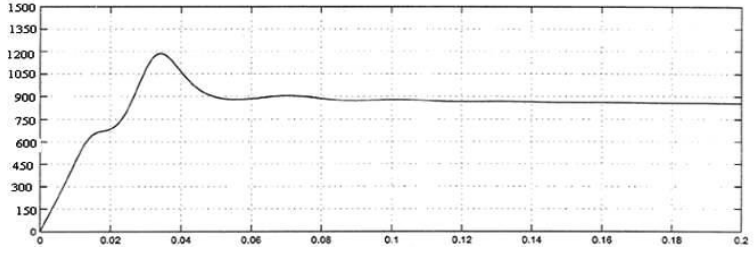

Fig. 23. Motor speed at full load with PFC

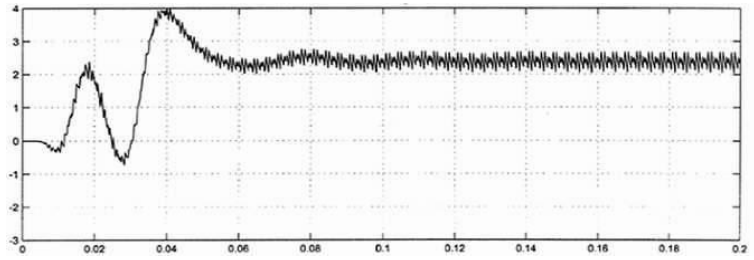

Fig. 24. Motor torque at full load with PFC

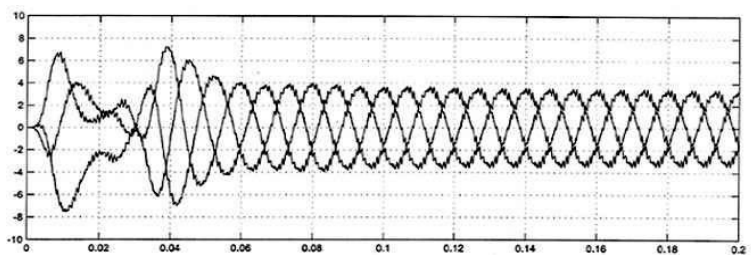

Fig. 25. Three phase rotor currents at full load without PFC

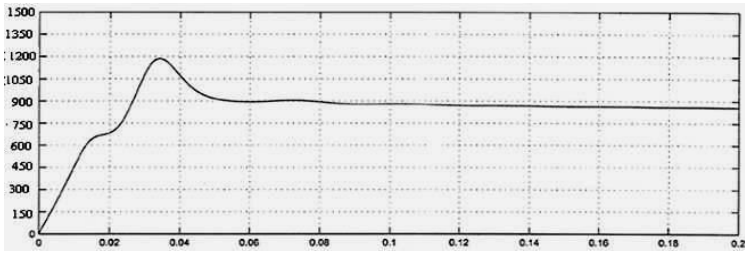

Fig. 26. Motor speed at full load without PFC

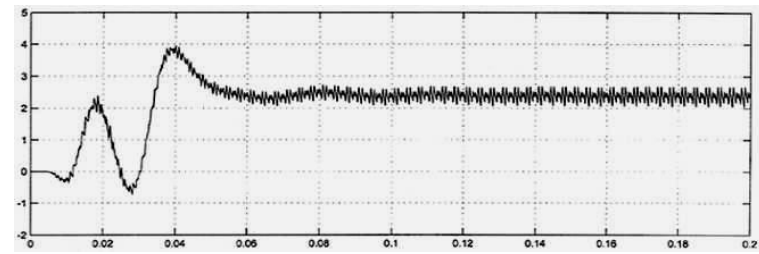

Fig. 27. Motor torque at full load without PFC
TABLE I: COMPARISON OF PARAMETERS WITH PFC CONTROL AND WITHOUT PFC CONTROL

\begin{tabular}{|c|c|c|c|c|c|c|}
\hline \multirow[b]{2}{*}{$\begin{array}{c}\text { Descripti } \\
\text { on }\end{array}$} & \multicolumn{2}{|c|}{ No Load } & \multicolumn{2}{|c|}{ Half Load } & \multicolumn{2}{|c|}{ Full Load } \\
\hline & $\begin{array}{c}\text { Without } \\
\text { PFC } \\
\text { control }\end{array}$ & $\begin{array}{c}\text { With } \\
\text { PFC } \\
\text { Cont } \\
\text { rol } \\
\end{array}$ & $\begin{array}{l}\text { Withou } \\
\text { t PFC } \\
\text { control }\end{array}$ & $\begin{array}{c}\text { With } \\
\text { PFC } \\
\text { Cont } \\
\text { rol } \\
\end{array}$ & $\begin{array}{c}\text { Without } \\
\text { PFC } \\
\text { Control }\end{array}$ & $\begin{array}{c}\text { With } \\
\text { PFC } \\
\text { Control }\end{array}$ \\
\hline Input PF & $0.77 \%$ & $\begin{array}{l}1.00 \\
\%\end{array}$ & $0.77 \%$ & $\begin{array}{l}1.00 \\
\%\end{array}$ & $0.77 \%$ & $1.00 \%$ \\
\hline $\begin{array}{l}\text { THD in } \\
\text { i/p } \\
\text { Current (1 } \\
-\Phi)\end{array}$ & $\begin{array}{l}110.63 \\
\%\end{array}$ & 5.12 & $\begin{array}{l}110.63 \\
\%\end{array}$ & $\begin{array}{l}5.12 \\
\% \\
\end{array}$ & $\begin{array}{l}110.63 \\
\%\end{array}$ & $5.12 \%$ \\
\hline $\begin{array}{l}\text { THD in } \\
\mathrm{o} / \mathrm{p} \\
\text { Voltage } \\
\text { of } \\
\text { Converter }\end{array}$ & $\begin{array}{l}120.30 \\
\%\end{array}$ & $\begin{array}{l}1.50 \\
\% \\
\end{array}$ & $\begin{array}{l}120.30 \\
\%\end{array}$ & $\begin{array}{l}1.50 \\
\% \\
\end{array}$ & $\begin{array}{l}120.30 \\
\%\end{array}$ & $1.50 \%$ \\
\hline $\begin{array}{l}\text { THD In } \\
\text { i/p Phase } \\
\text { A Current }\end{array}$ & 56 & 20 & 29.15 & 6.27 & 29.55 & 2.57 \\
\hline $\begin{array}{l}\text { THD In } \\
\text { i/p Phase } \\
\text { B Current }\end{array}$ & 53 & 25 & 28.75 & 7.86 & 28.1 & 2.59 \\
\hline $\begin{array}{l}\text { THD In } \\
\text { i/p Phase } \\
\text { C Current }\end{array}$ & 52 & 21 & 34.08 & 3.96 & 32.9 & 2.52 \\
\hline $\begin{array}{l}\text { THD In } \\
\text { i/p Line } \\
\text { A-B } \\
\text { Voltage }\end{array}$ & 82 & 39 & 81.1 & 38.4 & 81.15 & 38.4 \\
\hline $\begin{array}{l}\text { THD In } \\
\text { i/p Line } \\
\text { B-C } \\
\text { Voltage }\end{array}$ & 82 & 38 & 83.74 & $\begin{array}{l}39.0 \\
3\end{array}$ & 83.52 & 38.96 \\
\hline $\begin{array}{l}\text { THD In } \\
\text { i/p Line } \\
\text { C-A } \\
\text { Voltage }\end{array}$ & 73 & 37 & 72.67 & $\begin{array}{l}37.4 \\
9\end{array}$ & 72.74 & 37.53 \\
\hline $\begin{array}{l}\text { Steady } \\
\text { State } \\
\text { Torque }\end{array}$ & 0 & 0 & 1.1 & 1.2 & 1.8 & 1.9 \\
\hline $\begin{array}{l}\text { Max. } \\
\text { Torque } \\
\text { reached }\end{array}$ & 3.1 & 3.1 & 2.2 & 2.5 & 3 & 3.2 \\
\hline $\begin{array}{l}\text { Steady } \\
\text { State } \\
\text { Speed }\end{array}$ & 1 & 1 & 0.7 & 0.75 & 0.7 & 0.75 \\
\hline $\begin{array}{l}\text { Max. } \\
\text { Speed } \\
\text { reached }\end{array}$ & 1 & 1.1 & 0.8 & 0.8 & 0.8 & 0.8 \\
\hline
\end{tabular}

The Discussions are summarized as per observation of the results

- The Input Power Factor increased by using PFC correction technique when compared to without PFC correction technique.

- THD in the Input Current and THD in the Converter Output Voltage decreased drastically by using PFC correction technique when compared to without PFC correction technique.

- The high sharp currents changed to sinusoidal currents when PFC correction technique is used.

- Peak, Steady State values of the Input Current are less by using PFC correction technique when compared to without 
PFC correction technique. The Values of the above parameters have remained unchanged for all loads.

- The THD of the Input Phase Currents and Line Voltages decreased drastically by using PFC correction technique when compared to without PFC correction technique.

- The Value of the THD of the Input Phase Currents has decreased as the load increased with and Without PFC for all loads.

- There is no change in the Peak Input and Output Currents of the Motor with and Without PFC for all loads.

- The Steady State Rotor Phase Currents, Steady State and Maximum Torque has increased with the load and no change in the values for with and Without PFC. There is no change in the speed of the Motor with and Without PFC

\section{CONCLUSIONS}

The Variable Voltage and Variable Frequency (VVVF) drive (Induction Motor) has been developed which is fed from a converter, 3 phase inverter and which has unity input power factor capability using PFC Technique. The Performance of the drive is studied implementing PFC Technique and without PFC Technique. The drive is run at different loads (No Load, Half Load and Full Load) implementing with and without PFC Techniques. The Input Power Factor is Unity at all Loads using PFC Technique. The Total Harmonic Distortion of the
3 - $\Phi$ Rotor Currents has decreased and hence Power Factor has increased for all Loads when PFC Technique is used when compared without PFC Technique. Overall the performance of the drive is improved by using PFC Technique when compared without PFC Technique.

\section{REFERENCES}

[1] M. Morimoto, K. Oshitani, K. Sumito, M.Ishida, and S. Okuma, "New Single-Phase Unity Power Factor PWM Converter-Inverter System,' IEEE Power Electronics Specialists Conference Record, 1989

[2] B. Pandey, Singh and D. P. Kothari, "comparative evolution of single phase unity power factor AC-DC Boost converter topologies," IE(I) Journal.

[3] C. P. Henze and N. Mohan, "A digitally controlled AC to DC power conditioner that draws sinusoidal input current," IEEE-PESE Conference Record, pp. 531-540. 1986.

[4] S. Nonaka and Y. Neba, "A PWM GTO current source converter-inverter system with sinusoidal inputs and outputs," 22th IEEE-IAS Annual Meeting Conference Record, pp. 247-252, 1987.

[5] B. T. Ooi, J. W. Dixon A. B. Kulkarni, and N. Nishimoto, "An Integrated AC drive system using a controlled-currentPWM rectifier/Inverter Link," IEEE-PESCI Conference Record, pp. 494-501,1986.

[6] A. R. Prasad, P. D. Ziogas, and S. Manias, "an Active Power Factor Correction Technique for Three-Phase Diode Rectifiers," IEEE Transactions on Power Electronics, vol. 6, no. 1, pp. 83-92, 1991.

[7] Y. Suh and T. A. Lipo, "Modelling and analysis of instantaneous and reactive power for PWM AC/DC converter using generalized unbalanced network," IEEE Trans. on Power Delivery, vol. 21, no. 3 , pp.1530-1540, 2006 